\title{
ANALISIS KEBUTUHAN GURU SMP MENGENAI METODE PEMBELAJARAN FLIPPED CLASSROOM
}

\author{
Ria Asep Sumarni ${ }^{1)}$, Yoga Budi Bhakti2), Irnin Agustina Dwi Astuti²), Dwi Sulisworo ${ }^{3)}$, M. Toifur ${ }^{3)}$ \\ 1)Program Studi Informatika, Fakultas Teknik dan IImu Komputer, Universitas Indraprasta PGRI Jakarta \\ ${ }^{2)}$ Program Pendidikan Fisika, Fakultas Matematika dan IImu Pengetahuan Alam, Universitas Indraprasta PGRI Jakarta \\ ${ }^{3)}$ Program Studi Magister Pendidikan Fisika, Universitas Ahmad, Dahlan Yogyakarta \\ Corresponding author : Ria Asep Sumarni \\ E-mail : (riaasepsumarni@gmail.com)
}

\section{Diterima 08 Oktober 2020, Disetujui 29 Oktober 2020}

\begin{abstract}
ABSTRAK
Perkembangan teknologi yang merambah dalam dunia pendidikan telah banyak ditandai dengan adanya inovasi-inovasi terbarukan yang dapat menunjang proses pembelajaran. Salah satunya adalah dengan adanya inovasi dalam pembuatan metode pembelajaran. Guru harus bisa melakukan suatu inovasi pembelajaran karerna, guru memiliki peranan sangat strategis dalam proses pembelajaran. Pembelajaran IPA di SMP wilayah Jadebotabek khususnya mata pelajaran Fisika masih mengggunakan metode ceramah, memberikan catatan, memberikan latihan soal hal ini dirasa kurang menarik dan sering membosankan karena kurangnya inovasi dalam metode pembelajaran. Tujuan dari penelitian ini untuk melakukan analisis kebutuhan dan melihat peran guru dalam mengembangkan metode pembelajaran IPA yaitu menggunakan metode Flipped Classroom. Metode yang digunakan metode penelitian deskriptif kualitatif yaitu dengan cara melakukan analisis kebutuhan. Data penelitian dikumpulkan melalui wawancara, dan penyebaran angket. Angket analisis kebutuhan diberikan kepada Guru IPA di SMP wilayah Jawa Tengah. Dari hasil penelitian diperoleh bahwa pengembangan metode pembelajaran Flipped Classroom perlu dilakukan di SMP wilayah Jawa Tengah. Hasil lainnya, guru juga menginginkan adanya pelatihan tentang penerapan metode pembelajaran Flipped Classroom untuk meningkatkan kualitas metode pembelajaran.
\end{abstract}

Kata kunci: kebutuhan guru; metode pembelajaran; flipped classroom.

\begin{abstract}
The development of technology that has penetrated into the world of education has been marked by the existence of renewable innovations that can support the learning process. One of them is the innovation in making learning methods. Teachers must be able to carry out a learning innovation because teachers have a very strategic role in the learning process. Science learning at Junior high school in Central Java area, especially Physics subjects, still uses method of lectures, giving notes, giving exercises, this is deemed less interesting and often boring due to the lack of innovation in learning methods. The purpose of this study is to conduct a need assessment and see the role of the teacher in developing science learning model usuing Flipped Classroom. The research method used is descriptive qualitative research method that is by way of need assessment by conducting interviews questionnaire and direct observation. A needs analysis questionnaire was given to the science teacher at Junior high school in Jawa Tengah area. From the research results, it was found that the development of the Flipped Classroom learning method needed to be carried out at Junior high school in Jawa Tengah area. The other result, teachers at school want training on the application of the Flipped Classroom learning method to improve the quality of learning methods.
\end{abstract}

Keywords: teacher needs; learning methods; flipped classroom.

\section{PENDAHULUAN}

Pada abad 21, terdapat perubahan sistem pembelajaran saat ini dengan masa lalu. Sebelum abad 21 pembelajaran dilakukan tanpa berpatokan dengan standar, sedangkan pembelajaran saat ini memerlukan standar yang dijadikan sebagai patokan/acuan untuk mencapai suatu tujuan pembelajaran. Adanya standar yang telah ditetapkan, setiap guru mempunyai pedoman yang telah terstandarisasi. Perubahan zaman saat ini diimbangi dengan kemajuan teknologi informasi dan sitem komunikasi yang semakin canggih. Pada awal abad ke 21 teknologi juga membawa perubahan dalam dunia pendidikan (Wijaya, Sudjimat, Nyoto, \& Malang, 2016)(Budiman, 2017). 
Perkembangan teknologi yang merambah dalam dunia pendidikan telah membuat adanya perubahan inovasi-inovasi terbarukan (Effendi \& Wahidy, 2019) (Kumalasani, 2018) yang dapat menunjang proses pembelajaran. Salah satunya adalah dengan adanya inovasi dalam pembuatan metode pembelajaran. Hal ini karena adanya perkembangan teknologi yang semakin pesat dan berdampak pada kehidupan kita.

Penggunaan Teknologi Informasi (TI) sebagai media pembelajaran sudah merupakan suatu tuntutan (Tekege, 2017) (Nahdi, Rasyid, \& Cahyaningsih, 2020) (Husaini, 2017). Walaupun perancangan media berbasis $\mathrm{TI}$ memerlukan keahlian khusus, bukan berarti media tersebut dihindari dan ditinggalkan. Media pembelajaran berbasis TI dapat berupa internet, intranet, mobile phone, dan CD Room/Flash Disk. Adapun komponen utamanya meliputi Learning Management System (LMS), dan Learning Content (LC) (Muhson, 2010).

Semakin pesatnya perkembangan teknologi didunia pendidikan, para guru juga harus lebih siap dalam mengimplementasikan inovasi media pembelajaran, sehingga materi dapat tersampaiak kepada peserta didik kita dengan baik. Kemampuan kreativitas dari guru dalam dunia pendidikan menjadi tuntutan penting, termasuk guru IPA SMP. Oleh karena itu, setiap Guru harus bisa melakukan suutu inovasi pembelajaran. Guru memiliki peranan sangat strategis dalam proses pembelajaran (Nasrulloh \& Ismail, 2018) (Sulistiyo, 2020). Guru sebagai pengampu salah satu subkajian mata pelajaran IPA, para guru dituntut memiliki empat kompetensi yang meliputi kompetensi pedagogik, kepribadian, sosial, dan profesional. Keempat kompetensi tersebut tidak berdiri sendiri-sendiri, melainkan saling berhubungan dan saling mempengaruhi. Kompetensi yang satu akan mendasari kompetensi yang lainnya (Utomo, 2013) (Darmadi, 2016) (Kurnia, 2018).

Guru merupakan tonggak paling penting dalam melakukan perubahan metode pembelajaran yang dapat memberikan perubahan yang positif dalam kegiatan pembelajaran di kelas. Prioritas pembelajaran dengan metode ceramah menyebabkan kit IPA dan media pembelajaran lainnya jarang digunakan, bahkan ada yang sampai rusak dalam tempat penyimpanan (Suja, 2011).

Metode Pembelajaran berbasis Flipped Classroom adalah salah satu metode pembelajaran yang berpusat pada siswa untuk meningkatkan efektifitas pembelajaran (Damayanti \& Sutama, 2016). Metode Flipped Classroom, mencakup aktivitas penilaian kebutuhan, penentuan konten dan hasil pembelajaran, dan memilih metode pendidikan dan penilaian yang tepat (Lockyer, Ward, \& Toews, 2005). Metode pembelajaran Flipped Classroom adalah suatu model pembelajaran dimana siswa diberikan materi belajar berupa video dan bahan bacaan yang akan diajarkan di kelas untuk dipelajari di rumah (Astuti, Bhakti, Sumarni, Sulisworo, \& Toifur, 2019) (Astra \& Khumaeroh, 2019) (Jensen, Holt, Sowards, Ogden, \& West, 2018). Pada saat proses belajar berlangsung, guru menjawab kebingungan dari tugas baca siswa dan memberikan soal latihan di kelas sambil memperhatikan cara kerja siswa serta memberikan pembahasan soal setelah proses pengerjaan soal selesai. Dengan kata lain, model pembelajaran flipped classroom adalah model pembelajaran dimana siswa mempelajari materi belajar di rumah dan mengerjakan soalsoal latihan di kelas (Abidin, 2019).

Adanya metode pembelajaran yang tepat dan menarik tentunya akan mempengaruhi kegiatan pembelajaran. Pada pembelajaran Flipped Classroom selain Guru dituntut untuk lebih kreatif, siswa pun juga dilatih untulk lebih mandiri dalam menyelesaikan masalah di mata pelajaran (Cheng, Ka Ho Lee, Chang, \& Yang, 2017) (Santikarn \& Wichadee, 2018). Kemampuan pemecahan masalah peserta didik dalam pembelajaran Flipped lassroom berbasis proyek tergolong tinggi, hal ini dilihat dari siswa yang lebih mudah memahamai materi (Ismiati, Sarwi, \& Marwoto, 2020).

Peneliti melakukan penelitian di beberapa Sekolah Menengah Pertama di Propinsi Jawa Tengah. Langkah awal yang kami lakukan adalah observasi. Observasi dilakukan pada Guru IPA di beberapa SMP yang mengajar mata pelajaran fisika. Pembelajaran IPA di beberapa sekolah khususnya mata pelajaran Fisika masih mengggunakan papan tulis, teksbook dan powerpoint, hal ini dirasa kurang menarik dan sering membosankan karena tidak adanya metode pembelajaran yang inovasi.

Berdasarkan hal diatas maka peneliti ingin mengetahui analisis kebutuhan guru menggunakan metode pembelajaran Flipped Classroom pada Guru IPA di SMP yang terletak di Propinsi Jawa Tengah. Analisis kebutuhan guru penting dilakukan untuk meningkatkan kualitas media pembelajaran (Azmi \& Rukun, 2020). Tujuan dari penelitian ini adalah untuk meninjau model pembelajaran apa saja yang digunakan dalam pembelajaran IPA di sekolah yang terletak di Propinsi Jawa Tengah. Metode pembelajaran dilakukan pendataan. Kemudian data tersebut dikumpulkan dan dilakukan 
analisis. Penggunaan metode tersebut juga turut dibahas dalam penelitian ini.

\section{METODE PENELITIAN}

Penelitian ini merupakan penelitian deskriptif kualitatif. Pada penelitian ini dilakukan analisis kebutuhan metode pembelajaran. Analisis dilakukan secara menyeluruh mengenai penggunaan metode pembelajaran di sekolah tersebut. Penelitian ini dilakukan pada bulan Maret-Agustus. Tempat penelitian yaitu berada di SMP yang terletak di Propinsi Jawa Tengah. Sample sekolah tersebut dipilih secara Purposive Sampling dengan alasan sekolah tersebut merupakan sekolah unggulan dan favorit di daerah tersebut.

Data diambil dengan teknik wawancara dan pengamatan secara langsung mengenai metode pembelajaran di sekolah tersebut. Wawancara dilakukan kepada guru mata pelajaran IPA dan siswa. Guru diberikan pertanyaan seputar penggunaan metode pembelajaran IPA di sekolah tersebut. Tahapan berikutnya adalah dengan melakukan observasi dengan cara mengamati secara langsung keadaan penggunaan metode pembelajaran tersebut di sekolah, fungsi observasi juga untuk memperkuat analisis.

Instrumen penelitian ini dibuat dengan memperhatikan 4 aspek yang terdiri dari (1) Jenis metode pembelajaran yang biasa digunakan; (2) Kelebihan metode pembelajaran yang biasa digunakan; (3) Kekurangan metode pembelajaran yang biasa digunakan dan (4) Kendala guru dalam menggunakan. Kelima aspek tersebut digunakan karena dianggap aspek utama yang perlu diamati dalam pelaksannan penggunaan metode pembelajaran IPA. Data hasil wawancara dilakukan analisis secara deskriptif. Analisis diarahkan kepada alasan rendah atau tingginya penggunaan metode pembelajaran. Hasil analisa data berupa uraian secara deskriptif.

\section{HASIL DAN PEMBAHASAN}

Setelah dilakukan wawancara dan observasi kepada guru IPA di Jenjang SMP, maka diperoleh data yang telah dirangkum pada tabel 1. Terlihat bahwa terdapat perbedaan dalam penggunaan metode pembelajaran pada pembelajaran IPA dan lingkungan. Hasil analisis kebutuhan menunjukan bahwa variasi penggunaan metode pembelajaran IPA di Sekolah Menengah Pertama yang terletak di Propinsi Jawa Tengah masih rendah.
Tabel 1. Hasil pengamatan pada aspek metode pembelajaran yang biasa digunakan oleh guru di beberapa Sekolah Menengah Pertama di Jawa Tengah

\begin{tabular}{cl}
\hline Wilayah sekolah & \multicolumn{1}{c}{$\begin{array}{c}\text { Metode yang } \\
\text { digunakan }\end{array}$} \\
\hline $\begin{array}{c}\text { Kabupaten } \\
\text { Semarang }\end{array}$ & Ceramah \& Diskusi \\
\hline Kota Semarang & $\begin{array}{l}\text { Drill Soal Latihan \& } \\
\text { Ceramah }\end{array}$ \\
\hline Wonosobo & $\begin{array}{l}\text { Demonstrasi \& } \\
\text { Diskusi }\end{array}$ \\
\hline Surakarta & $\begin{array}{l}\text { Ceramah \& Latihan } \\
\text { Soal }\end{array}$ \\
\hline
\end{tabular}

Tabel 2. Hasil pengamatan pada aspek frekuensi penggunaan metode pembelajaran di dalam kelas di beberapa Sekolah Menengah Pertama di Jawa Tengah

\begin{tabular}{cl} 
Wilayah sekolah & \multicolumn{1}{c}{$\begin{array}{c}\text { Pertama di Jawa Tengah } \\
\text { penggunaan } \\
\text { metode } \\
\text { pembelajaran }\end{array}$} \\
\hline Kabupaten & $\begin{array}{l}\text { Setiap materi } \\
\text { pelajaran yang berisi } \\
\text { kensep }\end{array}$ \\
\hline Kota Semarang & $\begin{array}{l}\text { Setiap pertemuan } \\
\text { dikelas }\end{array}$ \\
\hline \multirow{2}{*}{ Wonosobo } & $\begin{array}{l}\text { Pada materi yang } \\
\text { terdapat percobaan, } \\
\end{array}$ \\
& $\begin{array}{l}\text { selebihnya lebih } \\
\text { banyak ceramah }\end{array}$ \\
\hline Surakarta & $\begin{array}{l}\text { Hampir setiap } \\
\text { pertemuan di kelas } \\
\text { menggunakan } \\
\end{array}$ \\
& ceramah dan latihan \\
\hline
\end{tabular}

Tabel 3. Hasil pengamatan pada aspek Kelebihan metode pembelajaran yang biasa digunakan oleh guru di beberapa Sekolah

Menengah Pertama di Jawa Tengah

\begin{tabular}{|c|c|}
\hline Wilayah sekolah & $\begin{array}{l}\text { Metode yang } \\
\text { digunakan }\end{array}$ \\
\hline $\begin{array}{l}\text { Kabupaten } \\
\text { Semarang }\end{array}$ & $\begin{array}{l}\text { Lebih mudah } \\
\text { diterapkan dan lebih } \\
\text { banyak materi yang } \\
\text { tersampaikan }\end{array}$ \\
\hline Kota Semarang & $\begin{array}{l}\text { Siswa dapat } \\
\text { menyelesaikan soal } \\
\text { dengan baik dan } \\
\text { lebih simple }\end{array}$ \\
\hline Wonosobo & $\begin{array}{l}\text { Dapat mengajak } \\
\text { siswa lebih aktif } \\
\text { dalam pembelajaran }\end{array}$ \\
\hline Surakarta & $\begin{array}{l}\text { Lebih mudah } \\
\text { diterapkan dan siswa } \\
\text { lebih mudah dalam } \\
\text { menyelesaikan soal- } \\
\text { soal fisika }\end{array}$ \\
\hline
\end{tabular}


Tabel 4. Hasil pengamatan pada aspek Kekurangan metode pembelajaran yang biasa digunakan di beberapa Sekolah Menengah Pertama di Jawa Tengah

\begin{tabular}{cl}
\hline Wilayah sekolah & \multicolumn{1}{c}{$\begin{array}{c}\text { Metode yang } \\
\text { digunakan }\end{array}$} \\
\hline Kabupaten & $\begin{array}{l}\text { Siswa lebih pasif } \\
\text { dalam belajar }\end{array}$ \\
\hline \multirow{2}{*}{ Kota Semarang } & $\begin{array}{l}\text { Siswa lebih cepat } \\
\text { bosan setiap } \\
\text { pelajaran dan siswa } \\
\text { tidak aktif }\end{array}$ \\
\hline Wonosobo & $\begin{array}{l}\text { Materi dalam satu } \\
\text { semester tidak } \\
\text { tercapai }\end{array}$ \\
\hline \multirow{2}{*}{ Surakarta } & $\begin{array}{l}\text { Siswa merasa bosan } \\
\text { dengan pelajaran } \\
\text { dan bersifat pasif }\end{array}$ \\
\hline
\end{tabular}

Dari hasil wawancara dan observasi kepada guru yang terdapat pada tabel 1 sampai tabel 4 diatas. Hasilnya menunjukkan bahwa pembelajaran IPA pada Sekolah Menengah Pertama di Propinsi Jawa tengah cenderung masih menggunakan metode pembelajaran yang konvensional. Hal ini mengindikasikan bahwa pengembangan metode pembelajaran IPA oleh guru ataupun ahli pendidikan belum banyak dilakukan. Terlihat bahwa frekuensi penggunaan metode pembelajaran yang melibatkan siswa aktif sesuai perkembangan teknologi informasi masih sangat minim. Padahal materi IPA di jenjang Sekolah Menengah Pertama merupakan materi dasar yang mengandung banyak konsep penting (Angin, 2020) (Doyan, Susilawati, Bahri, Muhlis, \& Artayasa, 2019). Pembelajaran ini terjadi dikarenakan guru masih berfikir bahwa pembelajaran IPA dengan menggunakan metode konvensional sudah cukup (Saputro, Irwanto, Sri Atun, \& Wilujeng, 2019) (Ichsan, Sigit, \& Miarsyah, 2019) .

Materi pada pelajaran IPA Fisika di SMP yang perlu dipertimbangkan untuk dikembangkan dengan metode pembelajarn Flipped Classroom adalah pada materi suhu dan kalor. Pembelajaran IPA Fisika dengan materi suhu dan kalor memerlukan media yang sesuai dikarenakan banyak sekali miskonsepsi yang terjadi, media yang tepat unuk dikembangkan adalah video animasi. Dengan video animasi membuat materi yang abstrak menjadi lebih nyata dan mempermudah penjelasan yang cukup kompleks (Suyatna, 2019) (Cai, Liu, Wang, Liu, \& Liang, 2020) (Fitriani, Susilawati, \& Linda, 2020).

Pada jenjang SMP jelas terlihat bahwa penggunaan media pembelajaran berbasis digital masih belum banyak digunakan dikarenakan kondisi sarana dan prasarana di beberapa SMP yang masih belum memadai untuk mendukung proses pembelajaran dengan media digital. Ditambah lagi dengan peraturan di beberapa SMP yang melarang siswa membawa gadget ke sekolah atau ke dalam kelas memperburuk keadaan tersebut sehingga proses pembelajaran dengan media digital terhambat. Latar belakang peraturan tersebut dibuat oleh pihak sekolah adalah agar para siswa dapat focus dalam belajar dan tidak bermain gadget saat berada di lingkungan sekolah. Namun, seiring dengan perkembangan zaman dan teknologi, sangat penting untuk diperhatikan bahwa kebutuhan siswa SMP membutuhkan teknologi dalam mencari sumber informasi untuk menyelesaikan tugas. Dalam era modern seperti saat ini, usia siswa sekolah yang masuk kedalam kategori kaum millennial memerlukan proses pembelajaran yang bisa dilakukan tanpa harus bertatap muka di kelas melalui berbagai platform pembelajaran, dimana penyampaian informasi dilakukan menggunakan video dengan memanfaatkan teknologi yang ada, sedangkan diskusi banyak dilakukan di kelas sehingga pembelajaran lebih aktif, ini adalah konsep pembelajaran dari metode Flipped Classroom (Altemueller \& Lindquist, 2017) (Wei et al., 2020) (Bhakti, Astuti, Sumarni, Sulisworo, \& Toifur, 2019) (Lewis, Chen, \& Relan, 2018).

$$
\text { Selain pengembangan metode }
$$
pembelajaran yang lebih menitik beratkan kepada penggunaan teknologi dan keaktifan siswa dalam belajar, seharusnya guru sudah mulai membangun kebiasaan untuk melakukan diskusi. Karena sebaik apapun metode pembelajaran, jika guru tidak bisa membawa seluruh kelas untuk terlibat aktif dalam pembelajaran akan tidak berguna juga. Kegiatan diskusi yang aktif di kelas ini tentu sangat bagus bagi siswa dalam pembelajaran (Tharayil et al., 2018) (Nicol, Owens, Le Coze, Maclntyre, \& Eastwood, 2018) (Kawuri, Ishafit, \& Fayanto, 2019). Siswa bisa diminta untuk berdiskusi kemudian dilanjutkan membuat sebuah proyek yang berisi materi pembelajaran IPA. Setelah proyek tersebut selesai maka dapat dipresentasikan di depan kelas kepada teman-temannya. Selain melatih keterampilan siswa dalam hal berbicara di depan temantemannya, presentasi juga membuat siswa lebih bisa berkomunikasi satu sama lain dan menambah pengalaman siswa serta meningkatkan kemampuan psikomotorik siswa (Gunawan, Harjono, Hermansyah, \& Herayanti, 2019) (Setiyani, Churiyah, \& Arief, 2019) (Botelho, Gao, \& Jagannathan, 2019). Guru juga harus melakukan evaluasi yang melibatkan peran serta siswa sehingga dapat 
mengetahui apakah pembelajaran dengan metode yang diterapkannya membawa dampak yang baik atau tidak (Verloigne, Ridgers, De Bourdeaudhuij, \& Cardon, 2018) (Tuarez, Delgado, Delgado, \& Romero, 2019) (Öztürk, 2019).

\section{SIMPULAN DAN SARAN}

Metode pembelajaran IPA Fisika SMP pada sekolah di Propinsi Jawa Tengah, belum terlalu beragam masih banyak yang menggunakan metode pembelajaran konvensional. Para guru merasa kesulitan dalam mengembangkan metode pembelajaran yang mengintegrasikan teknologi dan pembelajaran yang aktif. Lambatnya proses pengembangan metode pembelajaran juga disebabkan guru tidak memiliki banyak waktu untuk mengembangkan metode pembelajaran lainnya.

Saran untuk Kedepannnya harus pembelajaran yang menintegrasikan teknologi dan pembelajaran yang aktif yaitu metode Flipped Classroom dengan mengadakan Workshop Metode Pembelajaran Flipped Classroom dikarenakan masih sangat sedikit variasi metode yang digunakan guru dalam pembelajaran.

\section{UCAPAN TERIMAKASIH}

Terima kasih kepada Kementerian Riset, Teknologi dan Pendidikan Tinggi yang telah membiayai kegiatan Penelitian Kerjasama Perguruan Tinggi (PKPT) Tahun 2020. Terimakasih juga kepada LLDIKTI III, Lembaga Penelitian dan Pengabdian Masyarakat Universitas Indraprasta PGRI, dan Universitas Ahmad Dahlan yang telah membantu kegiatan penelitian ini.

\section{DAFTAR RUJUKAN}

Abidin, M. (2019). Model Pembelajaran Flipped Classroom sebagai Upaya Peningkatan Kemampuan Penguasaan Rumus Transformasi Geometri. Journal on Pedagogical Mathematics, 1(2), 49-60.

Altemueller, L., \& Lindquist, C. (2017). Flipped classroom instruction for inclusive learning. British Journal of Special Education, 44(3), 341-358.

Angin, R. Z. P. (2020). Penerapan STEM Pada Pembelajaran IPA Materi Bioteknologi. Prosiding Seminar Nasional Pendidikan Biologi.

Astra, I. M., \& Khumaeroh, S. I. (2019). The effect of flipped classroom model on student's physics learning outcome in work and energy concept. Journal of Physics: Conference Series, 1318(1),
12070. IOP Publishing.

Astuti, I. A. D., Bhakti, Y. B., Sumarni, R. A., Sulisworo, D., \& Toifur, M. (2019). The implementation of flipped classroom models to increase self-reliance and motivation of student learning. International Journal of Scientific and Technology Research, 8(10), 36353639.

Azmi, R. A., \& Rukun, K. (2020). Analisis Kebutuhan Pengembangan Media Pembelajaran Berbasis Web Mata Pelajaran Administrasi Infrastruktur Jaringan. Jurnal Imiah Pendidikan Dan ..., 4, 303-314.

Bhakti, Y. B., Astuti, I. A. D., Sumarni, R. A., Sulisworo, D., \& Toifur, M. (2019). Flipped classroom as a millennial teaching model. Indonesian Review of Physics, 2(1), 22-27.

Botelho, M. G., Gao, X., \& Jagannathan, N. (2019). A qualitative analysis of students' perceptions of videos to support learning in a psychomotor skills course. European Journal of Dental Education, 23(1), 20-27.

Budiman, H. (2017). Peran teknologi informasi dan komunikasi dalam pendidikan. AlTadzkiyyah: Jurnal Pendidikan Islam, 8(1), 31-43.

Cai, S., Liu, C., Wang, T., Liu, E., \& Liang, J. (2020). Effects of learning physics using Augmented Reality on students' self-efficacy and conceptions of learning. British Journal of Educational Technology.

Cheng, X., Ka Ho Lee, K., Chang, E. Y., \& Yang, $X$. (2017). The "flipped classroom" approach: Stimulating positive learning attitudes and improving mastery of histology among medical students. Anatomical Sciences Education, 10(4), 317-327.

Damayanti, H. N., \& Sutama, S. (2016). Efektivitas Flipped Classroom Terhadap Sikap Dan Ketrampilan Belajar Matematika Di Smk. Manajemen Pendidikan, 11(1), 2. https://doi.org/10.23917/jmp.v11i1.179 9

Darmadi, H. (2016). Tugas, Peran, Kompetensi, dan Tanggung Jawab Menjadi Guru Profesional. Edukasi: Jurnal Pendidikan, 13(2), 161-174.

Doyan, A., Susilawati, S., Bahri, S., Muhlis, M., \& Artayasa, I. P. (2019). Pelatihan Pemantapan Konsep Materi Fisika dan Pengukuran Bagi Guru IPA di SMPN 9 Mataram. Jurnal Pengabdian Magister Pendidikan IPA, 2(2). 
Effendi, D., \& Wahidy, A. (2019). Pemanfaatan Teknologi dalam Proses Pembelajaran Menuju Pembelajaran Abad 21. PROSIDING SEMINAR NASIONAL PROGRAM PASCASARJANA UNIVERSITAS PGRI PALEMBANG.

Fitriani, O., Susilawati, S., \& Linda, R. (2020). Development of Interactive Learning Media using Autoplay Studio 8 for Hydrocarbon Material of Class XI Senior High School. Journal of Educational Sciences, 4(2), 296-308.

Gunawan, G., Harjono, A., Hermansyah, H., \& Herayanti, L. (2019). GUIDED INQUIRY MODEL THROUGH VIRTUAL LABORATORY TO ENHANCE STUDENTS'SCIENCE PROCESS SKILLS ON HEAT CONCEPT. Jurnal Cakrawala Pendidikan, 38(2), 259-268.

Husaini, M. (2017). Pemanfaatan teknologi informasi dalam bidang pendidikan (eeducation). MIKROTIK: Jurnal Manajemen Informatika, 2(1).

Ichsan, I. Z., Sigit, D. V., \& Miarsyah, M. (2019). Environmental learning based on higher order thinking skills: a needs assessment. International Journal for Educational and Vocational Studies, 1(1), 21-24.

Ismiati, I., Sarwi, S., \& Marwoto, P. (2020). Pola Dan Kemampuan Pemecahan Masalah Peserta Didik Melalui Pembelajaran Flipped Classroom Berbasis Proyek. ORBITA: Jurnal Kajian, Inovasi Dan Aplikasi Pendidikan Fisika, 6(1), 115. https://doi.org/10.31764/orbita.v6i1.184 7

Jensen, J. L., Holt, E. A., Sowards, J. B., Ogden, T. H., \& West, R. E. (2018). Investigating strategies for pre-class content learning in a flipped classroom. Journal of Science Education and Technology, 27(6), 523-535.

Kawuri, M. Y. R. T., Ishafit, I., \& Fayanto, S. (2019). Efforts to improve the learning activity and learning outcomes of physics students with using a problembased learning model. IJIS Edu: Indonesian Journal of Integrated Science Education, 1(2), 105-114.

Kumalasani, M. P. (2018). Kepraktisan penggunaan multimedia interaktif pada pembelajaran tematik kelas IV SD. Jurnal Bidang Pendidikan Dasar, 2(1A), $1-11$.

Kurnia, Y. (2018). Penilaian Kinerja Guru Menggunakan Metode Topsis. Journal Scientific and Applied Informatics, 1(3), 70-75.
Lewis, C. E., Chen, D. C., \& Relan, A. (2018). Implementation of a flipped classroom approach to promote active learning in the third-year surgery clerkship. The American Journal of Surgery, 215(2), 298-303.

Lockyer, J., Ward, R., \& Toews, J. (2005). Twelve tips for effective short course design. Medical Teacher, 27(5), 392395.

https://doi.org/10.1080/014215905000 86888

Muhson, A. (2010). Pengembangan Media Pembelajaran Berbasis Teknologi Informasi. Jurnal Pendidikan Akuntansi Indonesia, $8(2)$. https://doi.org/10.21831/jpai.v8i2.949

Nahdi, D. S., Rasyid, A., \& Cahyaningsih, U. (2020). MENINGKATKAN KOMPETENSI PROFESIONAL GURU MELALUI PENGEMBANGAN MEDIA PEMBELAJARAN BERBASIS TEKNOLOGI INFORMASI. BERNAS: Jurnal Pengabdian Kepada Masyarakat 1(2), 76-81.

Nasrulloh, I., \& Ismail, A. (2018). Analisis Kebutuhan Pembelajaran Berbasis Ict. Jurnal Petik, 3(1), 28. https://doi.org/10.31980/jpetik.v3i1.355

Nicol, A. A. M., Owens, S. M., Le Coze, S. S. C. L., Maclntyre, A., \& Eastwood, C. (2018). Comparison of high-technology active learning and low-technology active learning classrooms. Active Learning in Higher Education, 19(3), 253-265.

Öztürk, M. (2019). An Evaluation of an Innovative In-Service Teacher Training Model in Turkey. International Journal of Higher Education, 8(1), 23-36.

Santikarn, B., \& Wichadee, S. (2018). Flipping the classroom for English language learners: A study of learning performance and perceptions. International Journal of Emerging Technologies in Learning (IJET), 13(09), 123-135.

Saputro, A. D., Irwanto, Sri Atun, \& Wilujeng, I. (2019). The impact of problem solving instruction on academic achievement and science process skills among prospective elementary teachers. Elementary Education Online, 18(2), 496-507.

https://doi.org/10.17051/ilkonline.2019. 561896

Setiyani, T. W., Churiyah, M., \& Arief, M. (2019). Enhancing the Students' Critical Thinking Ability and Learning Outcome Through Poe Learning Model. Jurnal 
Ad'ministrare, 6(1), 61-72.

Suja, I. W. (2011). Analisis Kebutuhan Pengembangan Buku Ajar Sains SD Bermuatan Pedagogi Budaya Bali. Jurnal Pendidikan Dan Pengajaran, 44(1-3), 84-92.

Sulistiyo, S. (2020). Peran Guru Dalam Meningkatkan Motivasi Pembelajaran Matematika Sekolah Dasar Pada Siswa Kelas Tinggi. At-Ta'lim: Kajian Pendidikan Agama Islam, 2(1), 104113.

Suyatna, A. (2019). Future physics learning materials based on STEM education: Analysis of teachers and students perceptions. Journal of Physics: Conference Series, 1155(1), 12021. IOP Publishing.

Tekege, M. (2017). Pemanfaatan Teknologi Informasi dan Komunikasi dalam Pembelajaran SMA YPPGI Nabire. Jurnal FATEKSA: Jurnal Teknologi Dan Rekayasa, 2(1).

Tharayil, S., Borrego, M., Prince, M., Nguyen, K. A., Shekhar, P., Finelli, C. J., \& Waters, C. (2018). Strategies to mitigate student resistance to active learning. International Journal of STEM Education, 5(1), 7.

Tuarez, M. A. V., Delgado, M. A. C., Delgado, R. I. Z., \& Romero, J. E. V. (2019). Approaches to evaluation assumed by teachers on teaching process-learning. International Journal of Social Sciences and Humanities, 3(3), 60-70.

Utomo, U. (2013). Analisis Kebutuhan Guru Seni Musik Dalam Konteks Pelaksanaan Pembelajaran Berbasis Action Learning Di Sekolah. Harmonia Journal of Arts Research and Education, 13(2),

110-119. https://doi.org/10.15294/harmonia.v13i 2.2777

Verloigne, M., Ridgers, N. D., De Bourdeaudhuij, I., \& Cardon, G. (2018). Effect and process evaluation of implementing standing desks in primary and secondary schools in Belgium: a cluster-randomised controlled trial. International Journal of Behavioral Nutrition and Physical Activity, 15(1), 94.

Wei, X., Cheng, I.-L., Chen, N.-S., Yang, X., Liu, Y., Dong, Y., \& Zhai, X. (2020). Effect of the flipped classroom on the mathematics performance of middle school students. Educational Technology Research and Development, 1-24.

Wijaya, E. Y., Sudjimat, D. A., Nyoto, A., \& Malang, U. N. (2016). Transformasi pendidikan abad 21 sebagai tuntutan pengembangan sumber daya manusia di era global. Prosiding Seminar Nasional Pendidikan Matematika, 1(26), 263-278. 